\title{
PODE A FÍSICA SER UM BOM ÁRBITRO PARA QUESTÕES EPISTEMOLÓGICAS?
}

\author{
Roberto Leon Ponczek \\ Instituto de Física - UFBA \\ Salvador - BA \\ Departamento de Física - UEFS ${ }^{1}$ \\ Feira de Santana - BA
}

\section{Resumo}

Muitos pesquisadores têm refletido sobre a importância da Epistemologia para o entendimento da Física, e sobre seu ensino, mas a recíproca não é verdadeira. Poucos refletiram acerca da possibilidade de a Física contribuir para o bom entendimento da Epistemologia. Pretendemos mostrar como a Física pode ser útil para arbitrar seculares questões filosóficas acerca da origem do conhecimento: se este se dá pelos sentidos, como defende o Empirismo, ou pela razão, como defende o Racionalismo. Com alguns exemplos simples extraídos da mecânica newtoniana, mostraremos que existem correlações entre fatos sem que entre eles exista causalidade e vice-versa. Isso enfraquece a posição empirista ortodoxa frente à origem do conhecimento, abrindo-nos novos e bons argumentos contra um ensino indutivista-empirista, proposto por alguns conhecidos livros-texto de Física.

Palavras-chave: Empirismo; racionalismo; correlação; causalidade.

\footnotetext{
${ }^{+}$Can physics be a good referee for epistemological problems?

* Recebido: julho de 2008.

Aceito: março de 2009.

${ }^{1}$ Prof. Visitante do Departamento de Física da Universidade Estadual de Feira de Santana.
} 


\begin{abstract}
Many researchers have been thinking on the importance of Epistemology for the Physics understanding, and on its teaching, but the reciprocal is not true. Very few attempts were made concerning the possibility of Physics to contribute for a good understanding of Epistemology. We intend to show how Physics can be useful to arbitrate about an epistemological secular subject concerning the origin of the knowledge: if it is reached by the senses, as it defends the Empiricism, or by reason, as it defends the Rationalism. With some simple examples extracted from Newtonian mechanics, we will show that correlations exist among facts without causality and vice-versa it can exist a hidden causality linking facts without correlations, which weakens the orthodox empiricism position concerning the origin of the knowledge, opening new and strong arguments against a inductive-empiricist teaching, as proposed by some known Physics textbooks.
\end{abstract}

Keywords: Empiricism; rationalism; correlation; causality.

\title{
I. Introdução
}

Descreveremos nas seções de I a V, a célebre polêmica dos séculos XVII e XVIII entre racionalistas e empiristas acerca da origem do conhecimento, e será posta sob questionamento a possibilidade de as leis da mecânica newtoniana, que estabelecem um vínculo causal entre força e aceleração, poderem ser imediatamente estabelecidas pela experiência. Limitar-nos-emos a uma reflexão sobre o Empirismo e Racionalismo primordiais dos séculos XVII-XVIII, por três motivos. Primeiramente porque depois da grande síntese kantiana que culminou com o Criticismo, as duas escolas filosóficas se tornaram muito mais complexas, e as suas diferenças foram consideravelmente minimizadas por sucessivos movimentos dialéticos de aproximação entre tese e antítese. Ser-nos-ia assim praticamente impossível encontrar exemplos simples na Física que pudessem realçar suas diferenças, o que invalidaria o propósito principal de nosso artigo. O segundo motivo para que circunscrevamos o confronto apenas ao período citado, é que a Física newtoniana, que nos servirá como árbitro, é também uma criação científica deste mesmo período, restringindo-se a polêmica a um único momento histórico. Fi- 
nalmente, e talvez o mais importante dos motivos, é que, apesar da grande síntese kantiana e pós-kantiana ocorrida no século XIX entre essas duas escolas epistemológicas, muitos livros-texto de Física ainda adotam uma postura tão ou mais ortodoxa que os próprios criadores britânicos do empirismo do século XVII.

Nas seções IV e V, reforçar-se-á a ideia kantiana de que a causalidade ou é uma categoria a priori do entendimento ou, segundo Espinosa, um princípio ontológico da natureza, que constitui sua essência e inteligibilidade.

Na seção VI, buscaremos na música alguns exemplos simples de causalidade com ou sem correlação rítmica. Refletiremos sobre um duo instrumental executando uma partitura e, em seguida, o mesmo duo sendo regido por um maestro.

Na seção VII, o oscilador harmônico forçado equacionado pela mecânica newtoniana, nos permitirá extrair exemplos didáticos muito simples de correlação sem causalidade e, vice-versa, causalidade sem correlação entre força e aceleração.

A partir da seção VIII, as reflexões históricas seguida dos exemplos extraídos da Música e da Física, servir-nos-ão para uma cuidadosa revisão dos conceitos pedagógicos propostos por alguns conhecidos livros-texto de Física. Mostraremos que estes são excessivamente calcados num empirismo ortodoxo, e, às vezes até ingênuo, que ora impõe aos aprendizes exaustivos programas de experimentação, e ora os converte num feixe de reflexos condicionados, em detrimento das livres manifestações do espírito humano, que nem sempre deve submeter-se à repetição e ao condicionamento.

Deixaremos de lado as concepções mais avançadas das duas escolas, como o Sistema de Lógica Dedutiva de John Stuart Mill $(1806,1873)$ ou o Racionalismo crítico de Karl Popper (1902-1994), ou ainda as complexas interações epistemológicas entre o material empírico e teórico sugeridas por seu discípulo Imre Lakatos (1922-1974) em sua Metodologia dos Programas de Pesquisa, pois que destas não poderíamos extrair exemplos simples com finalidade pedagógica, perdendo-se assim a finalidade didática deste artigo. A introdução filosófica que se estende até a seção $\mathrm{V}$ é destinada a professores de Física não iniciados na História da Filosofia, enquanto que aqueles que já conhecem o tema poderão começar a sua leitura a partir da seção VI.

\section{O Racionalismo no século XVII e XVIII}

A partir do Renascimento, com as obras de Copérnico (1473, 1543), Kepler $(1571,1630)$ e Galileu $(1564,1642)$, o homem deixa de perceber o universo 
como produto de uma evolução teleológica e finalista, devida a um criador com vistas a conduzir o universo a um estado final de perfeição. Na nova visão de mundo pós-renascentista, o universo é entendido como cenário de leis universais da natureza, expressas matematicamente e que são as representações de um universo regido por processos causais de produção das coisas materiais, que devem a sua existência a outras preexistentes. Estas, por sua vez, são determinadas a existir por outras e assim indefinidamente. Com o Racionalismo do século XVII, e principalmente depois da consolidação da mecânica newtoniana, como teoria aceita da realidade física, as quatro causas aristotélicas (final, material, formal e eficiente) ficaram praticamente restritas a esta última. A evolução de um objeto no espaçotempo poderia ser prevista a partir das ações que este objeto sofre dos demais objetos.

Durante os séculos XVII e XVIII, as noções de causalidade foram abundantemente discutidas. A tendência mais generalizada entre os racionalistas foi a equivalência completa entre causa e razão segundo o lema "causa sive ratio" (causa, ou seja, razão). Por esse princípio, a relação objetiva entre causa e efeito é idêntica à existente entre princípio e consequência.

Segundo o racionalista Espinosa ou Spinoza (1632-1677), isso significa que, se A é causa de B, então a ideia de A implicaria necessariamente a ideia de B. Tudo que se passa no domínio do mundo material tem uma representação lógica, análoga no domínio do mundo das ideias. O princípio acima estabelece, assim, um princípio ontológico de causalidade no qual uma cadeia de eventos materiais correspondente a uma cadeia paralela de ideias que se implicam lógica e necessariamente. Trata-se, portanto, de um princípio realista de causalidade.

Leibniz (1646, 1716), juntamente com Espinosa e Descartes, considerado o maior dos racionalistas, expressou o mesmo princípio de forma um pouco distinta. Ele formulou um sistema filosófico baseado em quatro princípios de conhecimento. O primeiro deles é o princípio da razão, que se subdivide no principio da razão necessária e da razão suficiente. A razão necessária exige que qualquer explicação submeta-se à condição de não contraditoriedade, isto é, uma ideia não pode conviver jamais com a sua negação. Se concluo que $S \rightarrow P$ não poderei ao longo de minhas demonstrações deduzir que $\mathrm{S} \rightarrow$ não $\mathrm{P}$. A razão suficiente exige que, além de uma ideia ser consistente consigo mesma e com todas as demais, a coisa pensada exista realmente, ou seja, que tenha uma causa que a faça existir. Portanto, se concluo que um fenômeno A é causa de B, não posso concluir que A seja causa também do desaparecimento de B. Princípio que pode também ser colocado na sua forma original: posita causa positur effectus e sublata causa, tollitur effectus (posta a causa posto o efeito e cessada a causa cessa o efeito). Isto é, ne- 
nhum efeito poderia ocorrer ou permanecer existente sem a correspondente causa que o precede como também toda causa produz necessariamente seu efeito.

\section{Empirismo nos séculos XVII e XVIII: causalidade como experiência repetida}

Enquanto que os principais filósofos europeus do continente tais como Leibniz, Espinosa Descartes, Malebranche e Wolff, dentre outros, eram racionalistas unânimes em defender o princípio "causa sive ratio", bem como a prioridade da razão sobre a experiência, para os empiristas - em sua maioria britânicos, como F. Bacon (1561, 1626), Hobbes (1588, 1679), J. Locke (1632, 1704), D. Hume $(1711,1776)$, G. Berkeley $(1685,1753)$ - a causalidade era tão-somente uma ideia desenvolvida a partir da experiência de percepção repetida, sincrônica e regular de fenômenos sucessivos. As ideias, assim, decorrem uma das outras como princípio e consequência, porém nada garante que, no mundo real, os fenômenos decorram uns dos outros. A conexão é sempre entre ideias associadas às sensações, e não das coisas em si existentes no mundo, ao qual não atribuíam qualquer independência ou inteligibilidade. Era o começo da famosa contenda entre a filosofia continental racionalista e a filosofia insular empirista que alguns historiadores bem humorados denominaram de "guerra dos 100 anos".

O filósofo, político e historiador inglês John Locke, um contemporâneo de Newton, em 1689, no famoso livro Ensaio sobre o entendimento humano, sugere que todo o conhecimento surge da experiência e das sensações monitoradas pela razão, e não diretamente desta, como havia proposto Descartes e como defendiam Leibniz e Espinosa. Discordando ainda do filósofo francês, não haveria, segundo Locke, ideias inatas e nem inspirações divinas. A base para o conhecimento se dá através da experiência, e não da razão, sendo esta precedida por aquela. Inspiradas em Aristóteles, tornaram-se célebres suas citações "todas as crianças nascem como telas em branco", e "não há nada na mente, a não ser o que estava antes nos sentidos": é a experiência advinda dos sentidos que escreve a lousa do espírito humano.

Para outro empirista, o bispo anglicano George Berkeley, o que não é percebido pelos sentidos e depois representado por ideias, simplesmente não existe. Para alguém que nunca viu a Lua ela simplesmente nunca existiu, ou seja, esse est percipi (ser é ser percebido). A escola empirista de Berkeley levou ao imaterialismo filosófico.

O filósofo escocês David Hume leva mais adiante as ideias de Locke e Berkeley, abolindo completamente a existência independente de um "mundo real". 
Para Hume, tudo o que se pode conhecer surge das sensações e das percepções sensoriais, as quais denomina de impressões, e estas geram, por sua vez, ideias na consciência:

Imaginemos se (...) poderíamos ter inferido desde o inicio que uma bola de bilhar iria comunicar movimento por meio de impulsos, e que não precisaríamos ter aguardado o resultado (do choque) para nos pronunciarmos com certeza acerca dele. Tal é a influencia do hábito. (...) Nós nunca experimentamos, de fato, um objeto, apenas impressões de sua cor, forma, consistência, gosto, etc. da mesma forma, as coisas simplesmente acontecem uma depois da outra. Não podemos nem mesmo dizer que uma coisa determina que outra aconteça. Podemos observar uma coisa constantemente se seguindo à outra, mas não há conexão lógica entre as duas e nenhuma razão lógica pela qual devam acontecer em sequência no futuro. Não temos outra noção de causa e efeito a não ser a de certos objetos que estiverem sempre associados (HUME, D., 2003, p. 57-61, passim).

Outro exemplo clássico do filósofo escocês pode assim ser resumido: de tanto vermos uma pedra estilhaçar uma vidraça, toda vez que virmos uma pedra aproximar-se da vidraça associaremos, por hábito, a ideia de sua ruptura, não havendo implicação causal entre o movimento da pedra e a consequente ruptura da vidraça.

Locke, Hume e Berkeley chegam até a negar a causalidade, isto é, uma cadeia de causas e efeitos sucessivos no tempo e separados no espaço. Eles acreditam que o que consideramos como causalidade é, na verdade, puro hábito sensorial. Para os empiristas, não há, portanto, conexões causais factuais, mas associações de ideias extraídas da experiência sensorial.

\section{Kant e a causalidade como categoria a priori do entendimento}

Segundo Kant $(1724,1804)$, a causalidade é uma das subcategorias de entendimento que relaciona dois fatos exteriores, que ocorrem em sucessão temporal, como ligados por um processo de produção do segundo (efeito) pelo primeiro (causa), isto é, uma intuição fundamental e apriorística do entendimento para organizar os fenômenos segundo leis de necessidade no cenário espaço-temporal. Para Kant, portanto, a causalidade dá forma, unidade e conexão à própria experiência e, por consequência, a precede.

Os juízos que se podem fazer acerca de um sujeito são de duas naturezas: sintéticos e analíticos. Enquanto que os primeiros são sentenças nas quais o predicado acrescenta algo de empírico ao sujeito como "no vácuo, todos os corpos caem com a mesma aceleração" ou "este círculo tem $4 \mathrm{~cm}$ de raio", nos juízos a 
priori, o predicado apenas define o que é o sujeito ou lhe dá um atributo como "o círculo é lugar geométrico dos pontos do plano equidistantes de um ponto", ou seja, denomina-se de "círculo" algo que possui o atributo de ser o conjunto de pontos do plano que equidista de um ponto. Nos exemplos acima, os juízos sintéticos são a posteriori, enquanto que o analítico é a priori da experiência. Kant define a causalidade como um outro tipo de juízo que não se enquadra em nenhum dos casos anteriores, ao qual denominou de juizo sintético a priori. Quando dizemos, por exemplo: "um circulo é a figura gerada por um segmento de reta que gira em torno de uma de suas extremidades", definimos agora o círculo, não por um de seus atributos geométricos, mas pela sua gênese causal, dando-lhe, assim, um juízo sintético que relaciona necessariamente a existência de algo (o círculo) a alguma outra coisa distinta que a precede (o segmento em rotação), segundo uma regra invariante de produção (a rotação por uma de suas extremidades).

Da mesma forma, as equações da Física podem expressar ora juízos analíticos ora sintéticos. Quando escrevemos, por exemplo, que $\mathbf{a}=\mathbf{F} / \mathbf{m}$, estamos associando a aceleração de um objeto a uma configuração de forças que procede de sua vizinhança, sendo-lhe externa, constituindo-se, assim, um juízo sintético. No entanto, quando escrevemos que $\mathbf{a}=\mathbf{d v} / \mathbf{d t}$, estamos dando uma definição de aceleração, ou o nome com que designamos a derivada temporal da velocidade, o que nenhuma informação acrescenta ao nosso entendimento.

Vejamos um marcante exemplo dado pelo próprio Kant (1960) acerca da causalidade:

Tomemos a seguinte proposição: tudo o que acontece tem uma causa. No conceito de algo que acontece, penso, na verdade, em uma existência, diante da qual há passado tempo e de onde posso deduzir juizos analíticos. Mas o conceito de causa está completamente fora daqueles, indicando algo fora do acontecimento (...) Como, então, atribuir ao que acontece algo que the é completamente estranho? E como conhecer que o conceito de causa, ainda que não compreendido no de acontecer, a ele se refere e até lhe pertence necessariamente? O que é essa incógnita X em que se apoia o entendimento quando crê descobrir fora do conceito um predicado que lhe é alheio e, no entanto, unido a ele? Não pode ser a experiência(grifo nosso), posto que a referida proposição reúne as duas ideias (o que acontece e algo que lhe antecede) não só de um modo geral como também com o caráter de necessidade, ou seja, a priori (KANT, 1960, p.156). 


\section{Quem afinal está certo: o Empirismo ou o Racionalismo?}

Será a causalidade, como defende Kant, uma operação necessária do intelecto que precede a experiência atribuindo a gênese de um fenômeno a outro que o precede? Será ainda um princípio ontológico da natureza em si, como defende Espinosa? Ou, pelo contrário, será a causalidade, segundo Locke e Hume, uma mera percepção sensorial repetida de eventos que entre si objetivamente nada têm em comum? A causalidade existe no mundo de fato ou apenas em nossa consciência?

Para os racionalistas, a razão opera, pois com princípios inatos, atemporais e de validade universal que precedem a experiência. Leibniz rejeita o empirismo de Locke, pois, para ele, a experiência advinda dos sentidos só cria a ocasião para o conhecimento dos princípios inatos. Parafraseando Locke, diz Leibniz: "Nada há no intelecto que não tenha passado primeiro pelos sentidos ... a não ser o próprio intelecto" e acrescenta no prefácio de sua famosa obra Novos Ensaios sobre o Entendimento Humano:

Só a razão é capaz de encontrar finalmente conexões certas na força das consequências necessárias, o que dá muitas vezes a possibilidade de prever o acontecimento sem ter necessidade de experimentar as conexões sensiveis das imagens (...)(LEIBNIZ, 1992, p. 4-5).

\section{Exemplo musical: causalidade, correlação e racionalidade numérica}

A partir deste ponto, nos permitiremos fazer uma crítica mais quantitativa acerca da polêmica entre racionalistas e empiristas do século XVII. Empregaremos para tal algumas propriedades físicas e matemáticas de dois ou mais fenômenos periódicos sincronizados e, na seção seguinte, iremos além, extraindo da mecânica newtoniana exemplos e contraexemplos simples de fenômenos periódicos sincronizados e outros que, embora completamente dessincronizados, podem estar vinculados causalmente. Com esse procedimento, acreditamos que a Física poderá arbitrar até que ponto a causalidade pode ser considerada como mera experiência de repetição (empiristas clássicos), ou se, pelo contrário, é uma operação necessária da natureza (Espinosa) ou ainda do entendimento (Kant). Questionaremos também os limites de validade filosófica desse procedimento. 
Imaginemos dois fenômenos intermitentes e periódicos, ou seja, que se repetem em tempos regulares $\mathrm{T}_{1}$ e $\mathrm{T}_{2}$, como, por exemplo, os sons de dois instrumentos musicais. Se existirem dois números inteiros $n_{1}$ e $n_{2}$ tais que:

$$
\mathrm{n}_{1} \cdot \mathrm{T}_{1}=\mathrm{n}_{2} \cdot \mathrm{T}_{2} \text {, }
$$

o que é o mesmo que afirmar que a razão $\mathrm{T}_{1} / \mathrm{T}_{2}$ é um número racional, os dois sons ocorrerão simultaneamente, sempre após $\mathrm{n}_{1}$ repetições do primeiro ou $\mathrm{n}_{2}$ do segundo estando em nítida correlação e embora podendo ser independentes entre si, darão a quem os ouve uma sensação de vínculo, assim como dois instrumentos tocando "no mesmo ritmo". No entanto, se a razão entre os períodos é um número irracional (que não pode ser escrito na forma da eq. 1), jamais os fenômenos voltarão a ser simultâneos pulsando sem sincronia, como dois músicos tocando "fora de ritmo". O ouvinte terá uma forte sensação de independência e desvinculação entre os dois sons.

\section{VI.1 Um violino e uma flauta tocando uma partitura}

Poderíamos imaginar nesse exemplo que $\mathbf{v}$ e f são um violino e uma flauta que tocam uma partitura na qual está escrito que, a cada compasso (representado pelo símbolo $|. .|$.$) , o violino \mathbf{v}$ executa três notas musicais, enquanto que a flauta $\mathrm{f}$, duas notas. A partitura também indica que o primeiro compasso cabe a $\mathrm{v}$, com $\mathrm{f}$ em pausa. O primeiro som * do compasso $\mathbf{n}+\mathbf{1}$ do violino $\left(\mathbf{v}_{\mathbf{n}+\mathbf{1}}\right)$ será sempre

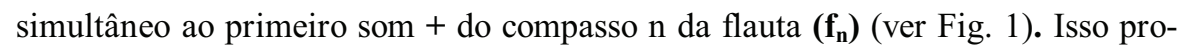
duzirá a quem os ouve um hábito de correlação e/ou vinculação entre os dois sons. Em outras palavras, é impossível saber apenas através das sensações se entre os sons v e f existe uma relação causal ou uma sincronia promovida pela partitura. $\mathrm{O}$ ouvinte poderia supor que os sons do violino causam os da flauta.

$$
\begin{array}{lccc}
\mathbf{V}_{1} & \mathbf{V}_{\mathbf{2}} & \mathbf{V}_{\mathbf{3}} & \mathbf{V}_{\mathbf{4}} \\
* * * * * * * & * * * * * * \mid \\
& +++|++|+ & +\mid \\
& \mathbf{f}_{\mathbf{1}} & \mathbf{f}_{\mathbf{2}} & \mathbf{f}_{3}
\end{array}
$$

Fig. 1 - Correlação entre os sons de um violino v e uma flauta f que pulsam em sincronia. Em cada compasso | | o violino executa três notas *, enquanto a flauta dois sons +. Os períodos estão na razão de 2/3. No primeiro compasso, a flauta permanece em pausa. 


\section{VI.2 Um regente, um violino e uma flauta}

Consideremos agora uma causa A que se repete regularmente com período $T_{A}$ produzindo desta feita dois efeitos $B$ e $C$ com períodos $T_{B}$ e $T_{C}$, de tal sorte que:

$$
\mathrm{n}_{\mathrm{A}} \mathrm{T}_{\mathrm{A}}=\mathrm{n}_{\mathrm{B}} \mathrm{T}_{\mathrm{C}}=\mathrm{n}_{\mathrm{C}} \mathrm{T}_{\mathrm{C}} .
$$

Os efeitos $\mathrm{B}$ e $\mathrm{C}$ têm períodos que obedecem também à condição de racionalidade e estarão a causa e os seus dois efeitos em sincronia ocorrendo simultaneamente após o tempo finito $\mathrm{n}_{\mathrm{a}} \mathrm{T}_{\mathrm{a}}$ (ver Fig. 2).

$$
\begin{array}{ll}
\text { A: } * * * * * * * * * \mid \\
\text { B: } & |++|++|++| \\
\text { C: } & |---|--|---|
\end{array}
$$

Fig. 2 - A causa A produz dois efeitos $B$ e C nas razões de 3/2 e 3/4. Existe uma relação causal $A \rightarrow B$ e $A \rightarrow C$, mas apenas uma sincronia entre $B$ e $C$. Neste exemplo, A pode ser o maestro e $B$ e $C$ dois instrumentos musicais.

No exemplo musical dado acima, A poderia ser um regente que a cada 3 movimentos com a mão indicaria a duração de um compasso, B seria um violino que deve tocar duas notas a cada compasso enquanto $\mathbf{C}$ é uma flauta que executa 4 notas. Um ouvinte que não estivesse vendo o regente, como numa gravação, por exemplo, poderia pensar que o instrumento $\mathbf{B}$ é a causa de $\mathbf{C}$ tocar, o que não é verdadeiro. $\mathrm{O}$ fato ocorre realmente quando se ouve persistentemente as gravações orquestrais.

Segundo o Empirismo clássico do século XVII, de tanto percebermos a sincronia entre os três fenômenos, acabaremos por acreditar que não há diferença alguma entre a produção de $\mathbf{B}$ por $\mathbf{A}$ e a sincronia entre $\mathbf{B}$ e $\mathbf{C}$. O argumento mantém-se ainda que a causa $\mathbf{A}$ cessasse. Nesse caso, $\mathbf{B}$ e $\mathbf{C}$ também cessariam, dando a impressão que se produzem e se $\mathrm{A}$ voltasse a atuar produziria mais uma vez seus efeitos B e C, reforçando a impressão de que estes se produzem.

Para os empiristas clássicos, portanto, de tanto perceber os sons $\mathrm{B}(+) \mathrm{e}$ $\mathrm{C}(-)$ juntos, porque se repetem sincronicamente ad infinitum (por terem seus períodos relacionados racionalmente entre si), eles estariam vinculados diretamente por uma condição causal. $\mathrm{Na}$ verdade, são apenas correlacionados, tendo ambos como causa comum o maestro $\mathrm{A}(*)$. 


\section{A Física como árbitro: causalidade e sincronia em um oscilador forçado}

Analisemos mais detalhadamente a questão acima levantada acerca da sincronia entre causa e efeito num dos sistemas mecânicos mais simples que é o oscilador de massa $\mathbf{m}$ e constante elástica $\mathbf{k}$, forçado por uma força periódica $\mathbf{F}=\mathbf{F}_{\mathbf{0}}$ sen wt e com atrito desprezível.

A equação que descreve o fenômeno se escreve:

$$
m \frac{d^{2} x}{d t^{2}}+k x=F_{o} \operatorname{sen}(w t)
$$

Consideraremos a causa como sendo a força oscilante $\mathbf{F}_{\mathbf{s}} \mathbf{s e n}(\boldsymbol{\omega} \mathbf{t})$ e o seu efeito mais imediato a aceleração a(t) do corpo de massa m. A solução dessa equação, para o corpo inicialmente em repouso na origem é:

$$
a(t)=\frac{F_{0} w}{m\left(w_{0}^{2}-w^{2}\right)}\left[w_{0} \operatorname{sen}\left(w_{0} t\right)-w \operatorname{sen}(w t)\right]
$$

na qual $w_{0}=(\mathbf{k} / \mathbf{m})^{1 / 2}$ é a frequência natural ${ }^{2}$ do oscilador harmônico, e $w$ a frequência da força oscilante.

Vemos, assim, que o efeito a(t) é a soma algébrica de duas senóides de frequências distintas cuja relação determinará de forma marcante as características da função. Analisemos as várias possibilidades:

a) $\omega_{o}=\omega$

No caso das frequências natural e forçada serem iguais, o numerador e denominador são nulos e a função a(t) torna-se indeterminada. Expandindo-se a função em série de Taylor até os termos de segunda ordem em $\delta \omega=\omega-\omega_{0}$, podese mostrar que:

$$
\mathrm{a}(\mathrm{t}) \cong \mathrm{Fo} / 2 \mathrm{~m}\left[\omega_{0} \mathrm{t} \cos \left(\omega_{0} \mathrm{t}\right)+\operatorname{sen}\left(\omega_{0} \mathrm{t}\right)(\operatorname{SYMON}, 1960) .\right.
$$

O primeiro termo é um co-seno, cuja amplitude cresce linearmente com o tempo e acaba mascarando o segundo termo, o que significa que o corpo, depois de certo tempo, oscilará com a frequência $\omega_{0}$ natural do oscilador, atingindo amplitudes cada vez maiores, podendo teoricamente chegar - na ausência completa de atrito - ao infinito. Acontece o chamado fenômeno da ressonância no qual a

\footnotetext{
${ }^{2}$ A frequência é mais propriamente $\omega / 2 \pi$.
} 
causa $\mathrm{F}$ e seu efeito a(t) oscilarão isocronamente numa situação que remete ao principio metafísico de Leibniz (1983) "causa aequat effectum”, pois a causa converte-se em seu efeito, transferindo-lhe a sua potência (ver Fig. 3).

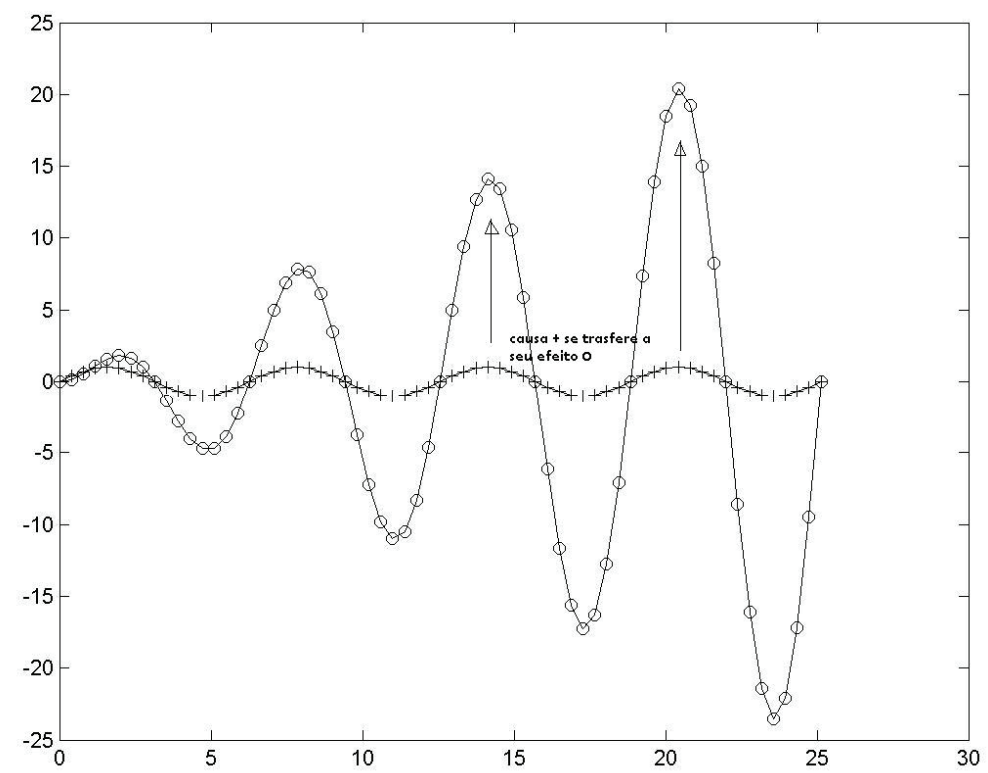

Fig. 3 - O fenômeno da ressonância: A força-causa (+) transfere-se à aceleração - efeito (o), havendo uma forte correlação entre ambos. Observando os fenômenos diretamente pelos sentidos ou olhando os gráficos o estudante poderá facilmente descobrir que são causa e feito.

b) $\omega_{\mathrm{o}} / \omega=\mathbf{n}_{\mathbf{0}} / \mathbf{n} \neq \mathbf{1}$ (eq. 1 )

Consideremos agora a situação em que a razão das frequências é um número racional diferente de 1 . Nesse caso, a aceleração $a(t)$ - bem como a posição e a velocidade do corpo - será a soma algébrica de duas senóides de frequências $\omega_{0}$ e $\boldsymbol{\omega}$ e será periódica com período $\mathbf{T}_{\mathbf{a}}=\mathbf{n}_{\mathbf{0}} \mathbf{T}_{\mathbf{0}}=\mathbf{n} \mathbf{T}$, o que é a condição de sincronia entre causa e efeito apresentada na seção anterior. A cada $\mathbf{n}$ oscilações da causaforça e $\mathbf{n}_{\mathbf{0}}$ oscilações do oscilador harmônico livre, causa e efeito se repetirão juntos, dando a quem os observa a sensação de estarem vinculados por algum nexo causal (ver Fig. 4). 


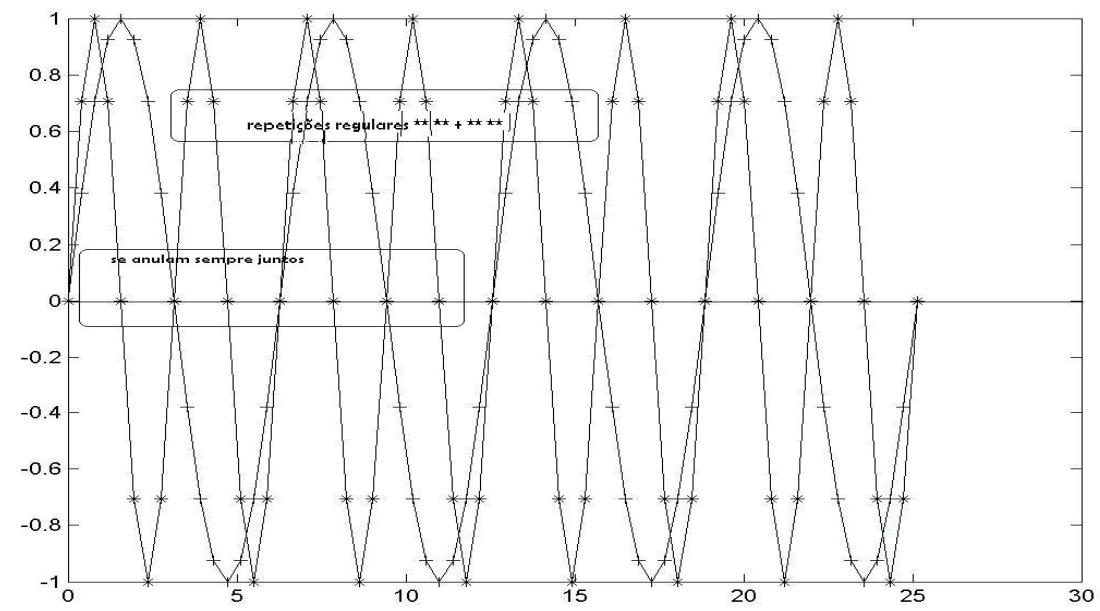

Fig. 4 - Num oscilador forçado, se a frequência da força-causa (*) guardar a proporção de 2:1 com a frequência natural, o efeito-aceleração (+) se anulará junto periodicamente. Os padrões de repetição de causa e seus efeitos são sempre regulares. Da mesma forma, um estudante poderá, sem dificuldade, descobrir a relação de causa e efeito.

\section{c) $\omega_{0} / \omega \neq \mathbf{n}_{\mathbf{0}} / \mathbf{n}$}

Consideremos, finalmente, a hipótese de que $\omega_{o}$ e $\omega$ são tais que não possam existir dois inteiros tais que satisfaçam a eq.1, ou seja, não há uma racionalidade numérica entre as duas frequências. Nesse caso a causa-força e efeitoaceleração jamais se repetirão juntos, estando sempre fora de fase - ou fora de ritmo, como diriam os músicos - dando a quem os observa uma sensação oposta aos dois casos anteriores: parece não haver nenhum vínculo entre as grandezas observáveis levando à crença de que força e aceleração são absolutamente independentes (ver Fig. 5). 


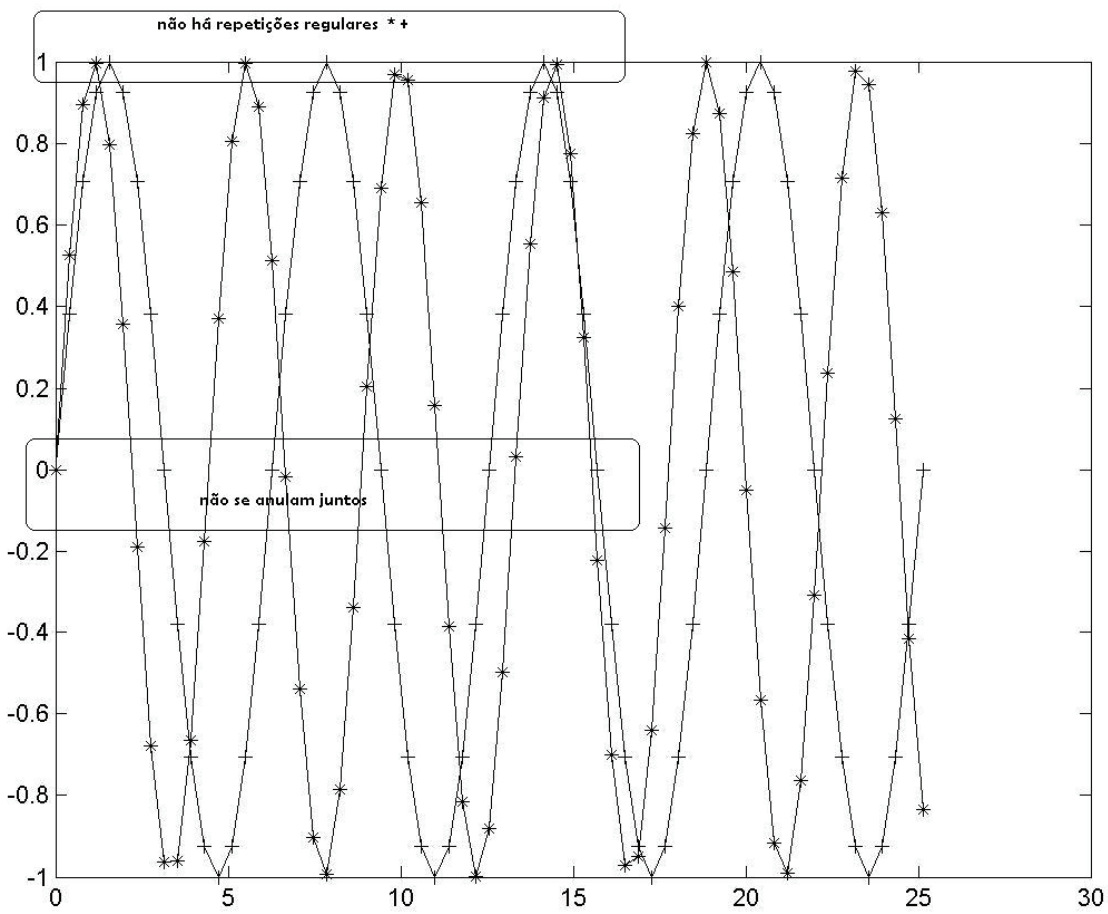

Fig. 5 - Se a razão de frequências for irracional, a força (*) e aceleração $(+)$, embora comecem juntas em $t=0$, nunca mais recomeçarão juntas, e não existem pontos nem padrões comuns de repetição. Alguém que apenas observe os dois fenômenos ou consulte esses gráficos não poderá concluir por uma relação de causa e efeito entre eles.

\section{Uma crítica a alguns de nossos livros-texto}

Nos casos (a) e (b) vistos acima (Fig. 4 e 5), quando uma causa externa vibra com a mesma frequência ou com frequências racionais em relação à frequência natural de um sistema, um observador (e, portanto, um estudante fazendo um experimento em sala de aula) pode, diretamente através de seus sentidos ou com auxílio de gráficos, perceber a correlação entre a causa e o seu efeito. A isocronia do primeiro caso e a sincronia do segundo produzem-lhe por repetição de 
experiências sensoriais, o hábito de associar a força à aceleração do corpo ${ }^{3}$. Nesse caso, os empiristas parecem estar corretos: o condicionamento nos leva a associar fenômenos aos pares, aos quais denominamos de causa e efeito, sem que na natureza nada ocorra que os vincule de fato, levando Hume à sua famosa expressão: "cause and effect are conjoined but not constrained" (causa e efeito estão juntos, mas não vinculados).

Entretanto, no caso (c) acima, em que causa e efeito vibram em frequências que não são múltiplas, (Fig. 5) nem os órgãos dos sentidos, nem os gráficos do fenômeno, poderão estabelecer vínculos ou correlações entre eles. Dessa forma, nenhum juízo empírico (sintético a posteriori) poderá ser estabelecido. Conclui-se assim que:

1 - Pode haver causalidade com correlação entre dois fenômenos (Fig. 3 e 4).

2 - Pode haver causalidade sem correlação entre eles (Fig. 5).

3 - Pode haver correlação sem causalidade entre eles (Fig. 1 e 2).

4 - Portanto, nem sempre será possível encontrar causalidade a partir dos fenômenos.

Dessa forma, um estudante que esteja num laboratório de aula experimental, observando o fenômeno, não poderá, por mais que se esforce, estabelecer uma relação de causa e efeito entre a força e a aceleração extraída apenas dos fatos empíricos, mesmo em um dos sistemas físicos mais simples da natureza, como um oscilador harmônico forçado com atrito desprezível. O que dizer de fenômenos mais complexos como osciladores acoplados, etc.?

Acreditamos, pois, que isso enfraquece a posição empirista ortodoxa, e, por conseguinte, a de um ensino de cunho empirista-indutivista, que é, no entanto, fortemente recomendado por parte dos livros-texto que costumam ser adotados nas Universidades brasileiras, como se depreende, logo nas páginas iniciais, de alguns textos que frequentemente constam das referências bibliográficas de boa parte dos planos de disciplinas de Física básica:

\footnotetext{
${ }^{3}$ A força oscilante aplicada ao corpo pode ser diretamente observada através de um dinamômetro ou "balança de feirante", presa ao corpo ao passo que a aceleração também pode ser observada através de um "acelerômetro", isto é, um pêndulo que pende do corpo, o qual defletir-se-á com um ângulo $\theta$ dado por $\operatorname{tg} \theta=\mathrm{a} / \mathrm{g}$.
} 
Tudo que sabemos do mundo fisico e sobre os princípios que governam seu comportamento foi aprendido da observação dos fenômenos da natureza (Sears, 1982, p. 3)

As leis da física são generalizações de observações e de resultados experimentais (TIPLER, 1978, p. 3).

A física, como ciência natural, parte de dados experimentais(...)através de um processo indutivo, formular leis fenomenológicas, ou seja, obtidas diretamente dos fenômenos observados (NUSSENSVEIG, 1981, p. 5).

Nas duas primeiras citações acima um "nem" antecedendo os quantificadores universais seria providencial... "Nem tudo que sabemos" (...), "Nem todas as leis" (...) A terceira citação acima de autoria de um de nossos mestres de juventude, prof. Nussensveig, tampouco resiste a um "nem": "A física, como ciência natural, nem sempre parte de dados experimentais(...)". importância:

Cabe-nos, agora, refletir sobre três questões epistemológicas de grande

1 - A causalidade habitaria uma realidade ontológica, como defendem Espinosa e Leibniz, conduzindo-nos a um princípio de causalidade racional e realista no sentido de uma "causalidade forte", isto é, ontologicamente dada nas coisas reais?

2 - Seria apenas um aparato mental necessário e apriorístico para que o intelecto possa ordenar e classificar os fenômenos de acordo com leis universais, como define Kant?

3 - Será uma mera associação de ideias provocadas pelo hábito de observação repetida, isto é apenas uma associação de ideias de experiências passadas, como defendem os empiristas ortodoxos e os livros-texto citados?

Por ora, podemos responder que a mecânica clássica, através dos exemplos que fornecemos, descarta a terceira posição epistemológica. Posição esta também contestada por G. Pascal:

Não é a experiência que nos capacita conhecer a relação objetiva dos fenômenos. Ao contrário, é só o conceito a priori da relação de causa e efeito que pode dar unidade objetiva à experiência, permitindo-nos perceber uma ordem real (...). Portanto, longe de ser um conceito derivado da experiência, como julgava Hume, a 
causalidade é a própria condição da experiência (PASCAL, 2001, p. 80, grifo nosso)

Quanto às duas primeiras questões, não encontramos ainda na Física clássica um poder de arbítrio.

\section{Conclusão}

A intermitência periódica acrescida à racionalidade numérica de dois ou mais fenômenos induz-nos a um hábito de percepção que poderá conduzir a mente a associar uma dependência causal entre eles. Nesse sentido, Hume e os empiristas clássicos, em alguns casos, estariam certos: a correlação observada induz à ideia de causalidade. Mostrou-se, no entanto, que certos fenômenos periódicos podem ser correlacionados, mas não vinculados causalmente (Fig. 1 e 2) enquanto que outros, pelo contrário, são causalmente vinculados e não correlacionados, como nos revela o oscilador forçado no qual força tem uma frequência irracional em relação à frequência natural da mola, (Fig. 5). Nesse caso, não existiria possibilidade de, através de uma experiência imediata dos sentidos, se estabelecer uma ideia de causalidade entre dois fenômenos, ou seja, a causalidade não poderia ser inferida ou induzida da mera repetição sensorial, porquanto esta não existe. Haveria, assim, necessidade de uma categoria apriorística para a organização dos fenômenos, em forma de leis universais e necessárias. Nesse sentido, a mecânica newtoniana faz a balança pender para a teoria kantiana de conhecimento.

No entanto, não faltam razões históricas para que os alunos de Física básica sejam espontaneamente mais empiristas do que racionalistas. A passagem de uma "física do senso comum de experiências repetidas" para uma "física de postulados e princípios racionais" é, assim, uma árdua tarefa pedagógica que os educadores devem perseguir com afinco. Um professor esclarecido deve de antemão prever as dificuldades com as quais irão se deparar seus alunos, no sentido que nem todas as ideias procedem diretamente da experiência sensorial, sendo dentre estas a causalidade uma das mais importantes. Ele saberá que historicamente coube a Kant, mais de um século depois dos Principia de Newton, aprimorar o Empirismo clássico.

Por outro lado, os mestres também não devem ser tão radicalmente empiristas quanto os citados textos de Física que recomendam exaustivos programas de experimentos, antes mesmo de se esboçar qualquer ideia ou teoria acerca do fenômeno. De fato, nem sempre o laboratório deve preceder a sala de aula. Embora os dados empíricos sejam determinantes para o teste de uma teoria, nem sempre 
(ou raramente) esta poderá ser diretamente inferida daqueles, como sugerem os autores acima citados. Os mestres também devem ser cautelosos para não fazer com que os alunos creiam que a relação entre força e a aceleração é tão nítida que pode ser facilmente estabelecida pelos sentidos ou exclusivamente pela experiência. Na verdade, a relação escolástica da força com a velocidade é mais intuitiva do que com a aceleração. Os bons professores devem instigar seus alunos ao pensamento livre que às vezes se move dando saltos, guiados apenas pela intuição, pois que, por detrás de fatos aparentemente desconexos, podem se ocultar leis e relações, e vice-versa, fatos correlacionados, às vezes, podem não ser unidos por causalidade. Dessa forma, a mecânica clássica, embora nada nos diga sobre o realismo ou não da causalidade, pôde-nos ser bastante útil como árbitro de interessantes reflexões acerca da origem do conhecimento humano, decidindo-se por um ensino não tão radicalmente empirista-indutivista.

\section{Referências bibliográficas}

BERKELEY, G. A treatise concerning the principles of human knowledge. Oxford: Oxford University Press, 1998.

BLACKBAUM, S. Dicionário Oxford de Filosofia. Rio de Janeiro: Jorge Zahar, 1997.

COSTABEL, P. Leibniz and Dynamics. (The text of 1692) N.York: Cornell University Press, 1973.

ENCYCLOPAEDIA BRITANNICA: Macropaedia. 15. ed. Chicago: Encyclopaedia Britannica, 1974.

ESPINOSA, B. Ética. Tradução: J de Carvalho. Coleção Os Pensadores. 2. ed. São Paulo: Abril Cultural, 1979.

HUME, D. Investigações sobre o entendimento humano e sobre os princípios da moral. Tradução: J. O. A. Marques. São Paulo: Editora Unesp, 2003.

KANT, I. Critica de la Razon Pura, Dialéctica Trascendental e Metodologia Trascendental. Buenos Aires: Lozada, 1960.

LALANDE, A. Dicionário Téenico e Crítico da Filosofia. São Paulo: Martins Fontes, 1990. 
LEIBNIZ, W. G. Discurso de Metafísica. Coleção Os Pensadores. São Paulo: Abril Cultural, 1983.

Essay on Dynamics. In: COSTABEL, P. (Org.). Leibniz and Dynamics (The text of 1692). Cornell: Cornell University Press, 1973.

Novos Ensaios Sobre Entendimento Humano. Tradução: L. J. Baraúna. Coleção Os Pensadores. São Paulo: Nova Cultural, 1992.

LOCKE, J. Ensaios sobre o entendimento humano. Coleção Os Pensadores. 2. ed. São Paulo: Abril Cultural, 1979.

MORA, J. F. Dicionário de Filosofia (verbete causa). Tradução: R.L. Ferreira e A. Cabral. São Paulo: Martins Fontes, 1998.

NEWTON, I. Princípios Matemáticos da Filosofia Natural. Tradução: C. L. Mattos et al. Coleção Os Pensadores. São Paulo: Nova Cultural, 1987.

NUSSEnZVEIG, H. M. Curso de Física Básica. São Paulo: Edgard Blucher, 1981.

PASCAL, G. O Pensamento de Kant. Tradução: R. Vier. 7. ed. Petrópolis:Vozes, 2001.

SEARS, F. Física 1. Rio de Janeiro: Livros Técnicos e Científicos, 1983.

SYMON, K. R. Mechanics. 2. ed. Addison-Wesley, 1960.

TIPLER, P. A. Física I. Rio de Janeiro: Guanabara Dois, 1978.

VOLTAIRE Elementos da filosofia de Newton. Tradução: M. G. S. do Nascimento. Campinas: Editora Unicamp, 1996.

WESTFALL, R. S. A Vida de Isaac Newton. The Life of Isaac Newton. Tradução: V. Ribeiro. Rio de Janeiro: Nova Fronteira, 1995. 